Practical X-ray measurements for medical purposes

This content has been downloaded from IOPscience. Please scroll down to see the full text. 1922 Proc. Phys. Soc. London 35 26D

(http://iopscience.iop.org/1478-7814/35/1/345)

View the table of contents for this issue, or go to the journal homepage for more

Download details:

IP Address: 128.192.114.19

This content was downloaded on 03/10/2015 at 07:40

Please note that terms and conditions apply. 


\title{
PRACTICAL X-RAY MEASUREMENTS FOR MEDICAL PURPOSES.
}

BY

\author{
Dr. Martin Berry.
}

$\S 1$. SINCE the science of radiology as a whole has now become an integral portion of many other sciences and arts, and since advances in the science can only result from physical investigations, no single sphere in which its utility has been manifested can claim the whole attention of those whose duty it is to investigate the general phenomena.

We who employ rays in the diagnosis and treatment of diseased conditions are apt to consider this as their chief application, but we must not overlook the other claims that are made on the attention of the physicist. To physics we owe the discovery of the rays, and to physics we have looked, and not in vain, for further advances. At the same time it behoves every medical man who practises radiology to understand not only the biological effects of radiations, but also the physical conditions under which they are produced, and the various devices by which the characteristics of the rays can be altered.

Medicine has particular limitations of its own to impose which may possibly be lost sight of during general physical investigations. When dealing with inanimate objects it is immaterial whether an exposure lasts three hours, three days or three weeks, but this is not so in the case of patients. An even more important limitation is the possibility, or rather probability, in inexpert hands of causing active damage. Whilst it is true that journalistic enterprise has resulted in awakening needless. alarm in the minds of the public, yet we must remember that the margin between inefficient and excessive dosage is narrow, and it is our bounden duty to make this margin as wide as we possibly can. This has been the purpose of the various measurements I have made, some of which are referred to in the present Paper.

One of the chief dangers which confronts us, and which imposes a limit on the dosage we can apply, is that of inflicting irreparable damage on the skin. In a very largo proportion of cases we are dealing with lesions situated deeply in the human econony, which lesions are known to require a certain dosage for their destruction. To fall far short of this dosage may result in actual stimulation of the growth, so that we are left to steer between the Scylla of under-dosage and the Charybdis of over-dosage.

The first and most important consideration for us is the depth dose-that is, the proportion of radiation received by a growth in the interior of the body as compared with that received by the skin and tissues covering it. The first and most obvious device to increase the depth dose is the method of cross-fire, by which the lesion is attacked through several ports of entry; but this method is not always available.

When we speak of practical measurements for medical purposes the subject really divides itself into measurements of the rays which are actually applied to the patient, so that we know what dose has been given, and measurements of the changes in the quality and quantity of radiation resulting from adjustments of the apparatus. It is chiefly the latter part with which.I am dealing in an attempt to 
show how a medical man who has to work with a particular set of apparatus may get the best out of it.

§2. The apparatus which was used for all the experiments is a twin coil working in conjunction with a mercury interrupter of the centrifugal jet type. Various makes of tubes have been used, all of them of the self-hardening, boiling-water variety.

The adjustments and variations possible on such apparatus are the amount of self-induction, the primary condenser capacity, the speed of the interrupter, and the duration of contact in the interrupter for each individual impulse ; of these, the interrupter speed is the most easily controlled and will be dealt with first. That considerable variations in the penetrating power of the radiation may result from simple changes of interrupter speed is shown by Table I., which is a single example of a large series giving similar results.

TABLE I.-Variation of Speed of Interruption.

Tube $P$. Filter $0.5 \mathrm{~mm}$. zinc. Field $6 \times 8 \mathrm{~cm}$. Measurements on iontoquantimeter. Figures are times of discharge in seconds. Focus to centre of ionisation chamber $37 \mathrm{~cm}$. Water tank $5 \mathrm{~cm}$. thick behind ionisation chamber in all tests. Penetration taken through $10 \mathrm{~cm}$. of water. Readings taken alternately without switching tube off. Boiling water tube.

\begin{tabular}{|c|c|c|c|c|c|}
\hline & & & & & Mean. \\
\hline 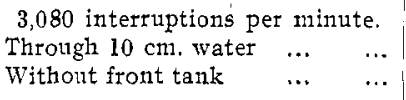 & $\begin{array}{r}25 \cdot 4 \\
7.8\end{array}$ & $\begin{array}{r}24.2 \\
8.0\end{array}$ & $\begin{array}{r}24 \cdot 4 \\
8.8\end{array}$ & $\begin{array}{r}24 \cdot 4 \\
8 \cdot 0\end{array}$ & $\begin{array}{c}24.6 \mathrm{sec} . \\
8.2,\end{array}$ \\
\hline $\begin{array}{l}2,640 \text { interruptions per minute. } \\
\text { Through } 10 \text { cnl. water } \\
\text { Without front tank }\end{array}$ & $\begin{array}{r}23.2 \\
8.6\end{array}$ & $\begin{array}{r}22.8 \\
9.0\end{array}$ & $\begin{array}{r}23.0 \\
7.8\end{array}$ & $\begin{array}{r}23 \cdot 6 \\
8 \cdot 4\end{array}$ & $\begin{array}{c}23.2 \mathrm{sec} . \\
8.5 \quad,\end{array}$ \\
\hline
\end{tabular}

Result,-12.8 per cent. penetration at 3,080 interruptions per minute and $16 \cdot 6$ per cent. pen:tration at 2,640 interruptions per minute.

Same tube and general arrangement as above.

\section{Comparison of Penetration by Kienbock Strips.}

Results, -15 per cent. penetration at 2,640 interruptions per minute.

17 per cent. penetration at 2,320 interruptions per minute.

The penetrations mentioned in these two tests are those which relate to the dose received by a lesion lying $10 \mathrm{~cm}$. under the skin surface as compared with that received by the skin itself. The tube was in rather too soft a condition for deep treatment of malignant conditions.

If the secondary current pass through an oscilloscope tube which is viewed in a rotating mirror, or is itself revolved, as in the ondoscope demonstrated by Dr. Hopwood, it will be seen that the phenomena are those of intermittent discharges through the tube with much longer intervening periods when no discharge is taking place, each wave of current representing a single interruption. In a gas X-ray tube these intervals are important, not only since they allow the heat generated at the focal spot to be distributed through the mass of the target, but even more since it is in these intervals that the air space between the cathode and target becomes de-ionised, and thus allows the rise of voltage on the tube terminals which gives to 
the electrons the velocity necessary to produce hard radiation. If we knew all the factors we should be able to say from the appearance of the oscilloscope discharge whether the resting period was too long, too short or just correct. But we can obtain the necessary information, without all these factors, by examining the radiation produced. Table I. shows such an examination at different speeds of interruption, carried out by readings on an iontoquantimeter and checked by another experiment with Kienbock strips. By taking a series of such measurements it is possible to obtain the optimum speed for each given set of working conditions. In the experiments in question readings were taken of the intensity of radiation received by an ionisation chamber, both with and without the interposition of $10 \mathrm{~cm}$. of water between the source of rays and the chamber, the rays having already passed through $0.5 \mathrm{~mm}$. zinc before reaching the water tank. In the experiments of Table I. the depth of dosage is given under the conditions laid down by the Erlangen technique.

Another point in connection with the interrupter which should be capable of variation is the duration of contact, and it is to be regretted that so many interrupters are constructed in which this adjustment is not possible. For any given set of working conditions there is one length of contact which is correct ; a shorter time of contact than this gives insufficient saturation, and a longer one passes an unnecessary amount of current through the primary, in addition to encroaching on the de-ionisation interval of the tube. My experiments on this point are not suffciently advanced for publication.

With regard to varying self-induction, as a rule this is only possible in very few steps, and on my own apparatus one degree is so obviously better than the others that it is the only one I have used.

Turning now to variations of the condenser. Much work has been done on this subject, but some of it is not applicable to apparatus already purchased, though it may be of great value to the manufacturer of such apparatus. In particular, the work of Taylor Jones was carried out under conditions different from those which obtain in a modern radio-therapeutic department. Seit $z$ and Wintz have published the results of tests with their own apparatus, showing a very marked optimum capacity. This optimum depends on so many factors that it cannot be transferred from one apparatus to another; the results of tests on my own apparatus are shown in Table II. In this series of measurements the only factor altered was the condenser capacity, and the influence of this variation is exceedingly marked. The figures show a steady rise in the primary current, whilst the secondary current only varies slightly, the extra amount of energy intake being expended largely in the form of increased voltage.

The lower part of the table shows an optimum at 3.97 microfarads, which is approximately the same as that obtained by various other series of tests. The columns headed "Air" and "Water "represent the time taken in seconds for the discharge of the iontoquantimeter, respectively without and with the interposition of $10 \mathrm{~cm}$. of water in the path of the rays between the filter and the ionisation chamber. The field of irradiation in these experiments was larger than that used in Table I., and the distance from focus to ionisation chamber was greater, hence the percentage penetration is greater. These experiments were carried out more nearly under my practical working conditions than those of Table I. As a general rule, I prefer a smaller number of fields each of larger area and a comparatively long focus-skin distance to the technique of a larger number of smaller fields with a shorter distance. 
TABLE II.-Variation of Primary Condanser.

Experimental Details :-Boiling water tube. Measured on iontoquantimeter. Focus to ionisation chamber $46 \mathrm{~cm}$. Diaphragm $6 \times 8 \mathrm{~cm}$. midway. Water tank $20 \mathrm{~cm}$. square and $10 \mathrm{~cm}$. deep. Wax block behind ionisation chamber. Filter $0.5 \mathrm{~mm}$. zinc. Spark gap $40 \mathrm{~cm}$ between points. Tube rheostat 12. Motor rheostat 7. Auxiliary theostat 7.5.

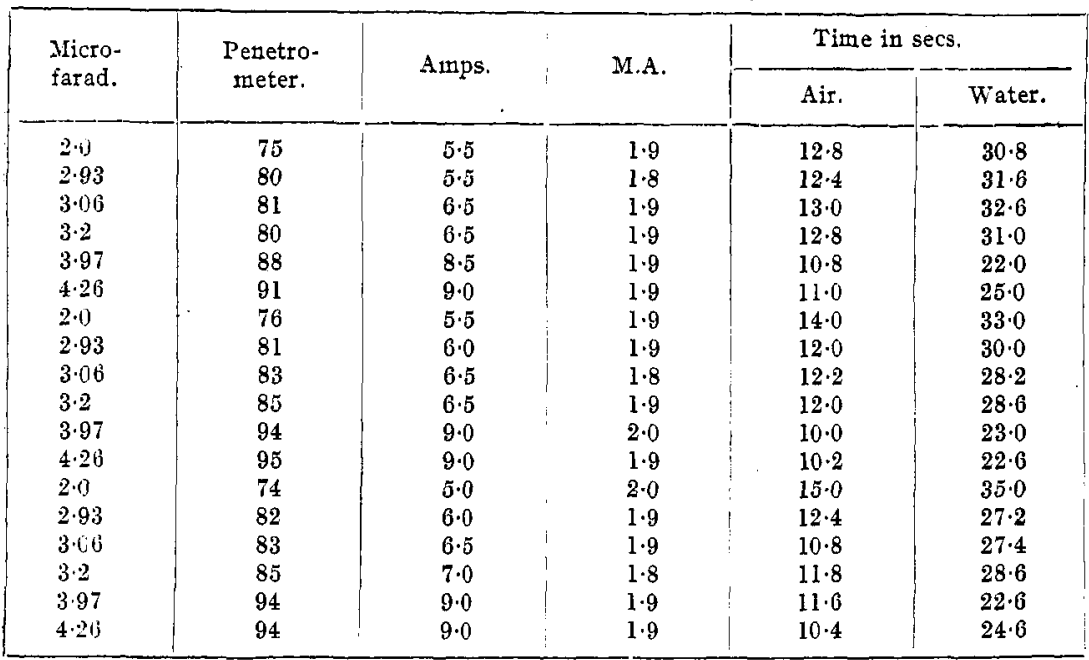

Above figures arranged under condenser capacity.

\begin{tabular}{|c|c|c|c|c|c|c|}
\hline Capacity, microfarad & $2 \cdot 0$ & $2 \cdot 93$ & $3 \cdot c 6$ & $3 \cdot 2$ & 3.97 & $4 \cdot 26$ \\
\hline No water $\quad \ldots$ & $\begin{array}{l}12 \cdot 8 \\
14 \cdot 0 \\
15 \cdot 0\end{array}$ & $\begin{array}{l}12 \cdot 4 \\
12 \cdot 0 \\
12 \cdot 4\end{array}$ & $\begin{array}{l}13.0 \\
12.2 \\
10.8\end{array}$ & $\begin{array}{l}12 \cdot 8 \\
12 \cdot 0 \\
11 \cdot 8\end{array}$ & $\begin{array}{l}10.8 \\
10.0 \\
11.6\end{array}$ & $\begin{array}{l}11 \cdot 0 \\
10 \cdot 2 \\
10 \cdot 4\end{array}$ \\
\hline Mean $\ldots$ & $13 \cdot 9$ & $12 \cdot 3$ & $12 \cdot 0$ & $12 \cdot 2$ & $10 \cdot 8$ & $10 \cdot 5$ \\
\hline 10 cy, water & $\begin{array}{l}30.8 \\
33.0 \\
35.0\end{array}$ & $\begin{array}{l}31 \cdot 6 \\
30 \cdot 0 \\
27 \cdot 2\end{array}$ & $\begin{array}{l}32 \cdot 6 \\
28 \cdot 2 \\
27 \cdot 4\end{array}$ & $\begin{array}{l}31 \cdot 0 \\
28.6 \\
28.6\end{array}$ & $\begin{array}{l}22 \cdot 0 \\
23 \cdot 0 \\
22 \cdot 0\end{array}$ & $\begin{array}{l}25 \cdot 0 \\
22 \cdot 6 \\
24 \cdot 6\end{array}$ \\
\hline Mean $\ldots, \quad \ldots$ & $32 \cdot 9$ & $29 \cdot 6$ & $29 \cdot 4$ & $29 \cdot 4$ & $22 \cdot 5$ & $24 \cdot 1$ \\
\hline Per cent, through water' & $42 \cdot 3$ & $41 \cdot 6$ & $40 \cdot 9$ & $41 \cdot 5$ & $48 \cdot 0$ & $43 \cdot 6$ \\
\hline
\end{tabular}

In addition to the figures in Table II. it may be stated that with a condenser of only 2 microfarads the working of the tube was most irregular and the conditions not suitable for treatment of a patient. The alternate spark-gap (between blunt points) was set at $40 \mathrm{~cm}$., and as the condenser capacity was raised sparks bridged this gap with increasing frequency until, at the two highest capacities used, they were almost continuous. I did not wish to alter the gap, but had this been done the figures for the larger capacities would have shown still greater superiority over the other figures. The readings were taken in the order given in the upper part of the table in order to climinate as far as possible any error due to variation of tube condition. 
§3. Let us assume now that we have produced a quality of radiation which we regard as suitable for application to a patient, and turn to some consideration regarding its application. Let us also remember that our primary object is to make the depth dose as large as possible compared with the skin dose. Though consideration of the patient's feelings and comfort causes us to shorten the time of dosage as much as possible, yet we must not sacrifice efficiency for this purpose.

One method of increasing the depth dose is to cover the surface of the body with a layer of some material which has approximately the same coefficient of absorption as the tissues. Rays are absorbed according to an exponential law, and therefore the actual amount of energy absorbed in the superficial layers is greater than that in the deeper layers. Add to this the fact that the superficial layers lie nearest to the source of origin of the radiation, and it is obvious that the amount of radiation affecting them is much greater than that affecting a corresponding layer in the depths. Since there is very good ground for believing that the biological effect is proportional to the amount of energy absorbed, we are in the position that the greatest absorption and biological effect occurs in the skin; and this limits the depth dose which we can apply. It is with the purpose of reducing this disparity as far as possible that the body surface may be covered with a layer of some centimetres of material to take up this strong absorption.

In most of the experiments designed to examine the distribution of ray intensity water has been used as an absorbing and scattering material, since it behaves in this respect similarly to body tissues. It is, however, rather inconvenient to cover the body surface with a layer of water, and other materials have been used. Paraffin wax has been employed extensively for this purpose. From Table III. it will be seen that paraffin wax is wholly unsuitable, and that its use for this purpose would give entirely fallacious ideas about actual dosage. Various compounds were tried as substitutes for wax, but the result of tests of the latest composition is not entirely satisfactory for two reasons. Firstly; because it still allows a rather greater percentage of radiation to pass through than water does; and, secondly, because it is not sufficiently plastic to be moulded casily to the contours of the patient. A formula for a mixture which would satisfy these two conditions would be a boon. It is fairly easy to evolve a formula to satisfy either condition, but it is essential that both should be complied with. If we are building up the surface of the body with a mass which we intend to consider as forming a homogeneous whole with the body for the purposes of calculation and measurement, it really must adapt itself to the surface without leaving air spaces; some portions of the body present great diffculties in this respect. At the same time, the material should be capable of retaining its shape without the necessity of enclosing it in bags or other containers. Possibly dough, which is the next material it is proposed to try, may prove suitable. In Germany a pulp of cellulose is used, but this does not retain its shape satisfactorily.

$\S 4$. One final point on which comment should be made is the importance of back-scattered radiation. Table IV. gives in its upper part the results of some measurements made with a water phantom, and, below,'a trial with Kienbock strips on a patient during an actual treatment. The importance of back-scattered radiation in practical therapy becomes most evident in cases where it may be diminished in the depths, such, for example, as in the treatment of a case of uterine cancer, where a gas-filled rectum lies behind the uterus. The skin always receives radiation scattered back from the subcutaneous tissues, and the amount of such radiation is 
well shown in the curves published by Prof. Dessauer, of Frankfort, to whom I am indebted for much useful information and assistance. This effect of backscattering calls for caution when radiating two skin fields close to each other.

TABLE III.-Comparison of Penetrations through Water, Paraffin Wax and Compo Wax.

Tube M. boiling water. Filter $0.5 \mathrm{~mm}$, zinc. Focus to ionisation chamber $33 \mathrm{~cm}$. Diaphragm $6 \times 8 \mathrm{~cm}$, at $23 \mathrm{~cm}$, from focus. Alternate spark gap $40 \mathrm{~cm}$. Readings taken alternately.

\begin{tabular}{|c|c|c|c|c|c|}
\hline \multicolumn{5}{|c|}{ Times of discharge of iontoquantimeter in seconds. } & Mean. \\
\hline $10 \mathrm{~cm}$. water in front and $5 \mathrm{~cm}$. behind & $22 \cdot 4$ & $22 \cdot 6$ & $22 \cdot 2$ & $22 \cdot 0$ & $22.3 \mathrm{sec}$. \\
\hline $10 \mathrm{~cm} . \mathrm{P}$. wax in front and $5 \mathrm{~cm}$. behind & $15 \cdot 4$ & $15 \cdot 6$ & $17 \cdot 0$ & $17 \cdot 2$ & $16 \cdot 3$ \\
\hline No front tank, wax behind ... & $7 \cdot 0$ & $7 \cdot 8$ & $7 \cdot 8$ & $8 \cdot 0$ & 7.6 \\
\hline
\end{tabular}

Result. $-34 \cdot 1$ per cent. transmitted through water and $46 \cdot 6$ per cent. through paraffin wax.

Experiment to Compare Paraffin Wax and Compo Wax with Water.

Tube $P$. boiling water. Other experimental arrangements as above. Dimensions of all tanks and wax blocks $20 \mathrm{~cm}$. square. Front tanks and blocks $10 \mathrm{~cm}$. thick, back tanks and blocks $5 \mathrm{~cm}$. thick. Times of discharge of iontoquantimeter in seconds. In all the experiments the back tank was water.

\begin{tabular}{|c|c|c|c|c|c|c|c|}
\hline & & & & & & & Mean. \\
\hline $10 \mathrm{~cm}$, of water in ftont & $\ldots$ & $\ldots$ & $\ldots$ & 23.9 & $23 \cdot 3$ & $24 \cdot 0$ & $23.7 \mathrm{sec}$. \\
\hline $10 \mathrm{~cm}$, of compo in front & $\ldots$ & $\ldots$ & $\ldots$ & $22 \cdot 6$ & $22 \cdot 5$ & $23 \cdot 0$ & $22 \cdot 7$ \\
\hline $10 \mathrm{~cm}$. of P. wax in front & $\ldots$ & $\ldots$ & $\ldots$ & $19 \cdot 4$ & $19 \cdot 6$ & $18 \cdot 8$ & $19 \cdot 3$ \\
\hline No block in front & $\ldots$ & $\ldots$ & $\ldots$ & $7 \cdot 6$ & $7 \cdot 2$ & $7 \cdot 2$ & $7 \cdot 3$ \\
\hline
\end{tabular}

Result.-Radiation transmitted through $10 \mathrm{~cm}$. water, 30.6 per cent. Radiation transmitted through $10 \mathrm{~cm}$. compo, $32 \cdot 1$ per cent. Radiation transmitted through $10 \mathrm{~cm}$. P. wax, 38.0 per cent.

TABLE IV.-Importance of Back-Scattered Radiation.

Tube P. boiling water. Filter $0.5 \mathrm{~mm}$, zinc. Focus to centre of ionisation chamber $37 \mathrm{~cm}$. $2,6 \pm 0$ interruptions per minute. 6.5 amps. in primary, 2.2 M.A. in secondary. Front water tank $20 \mathrm{~cm}$. square and $10 \mathrm{~cm}$. thick. Tank behind ionisation chamber $20 \mathrm{~cm}$. square and $5 \mathrm{~cm}$. thick.

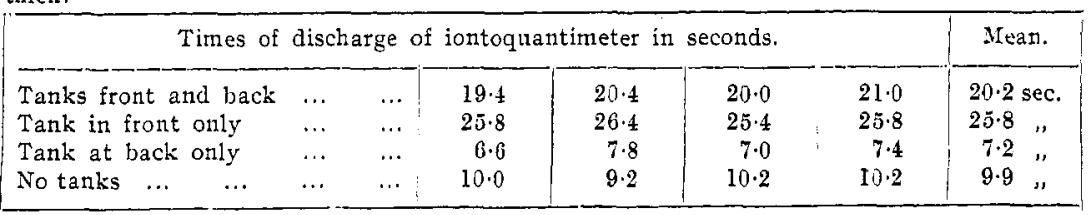

Resull.-The intensity in the ionisation chamber becomes increased by 27 per cent. if the rays have passed through $10 \mathrm{crn}$. of water, and by 37 per cent. if they have only passed through air between the filter and the iunisation chamber, these percentages being the amounts added by the radiation scattered back from the tank behind the ionisation chamber.

Experiment to show amount of back-scattered radiation under actual conditions of treatment. A field $6 \times 8 \mathrm{~cm}$. was being treated, and a Kienbock strip was placed with the sensitive surface downwards on the patient's skin $4 \mathrm{~cm}$. distant from the edge of the field. Its back was protected by thick lead, so that the only radiation it received was that back-scattered in the patient. Whilst the field received a dose of $26 \mathrm{X}$, the strip placed outside it showed $1.75 \mathrm{X}$.

A similar experiment under the same conditions showed $6.5 \mathrm{X}$ on the field and $0.5 \mathrm{X}$ on the strip. 
The figures of Table IV. speak for themselves. They have been selected from a large number of similar experiments. The trial by Kienbock strips on the skin of the patient shows that this effect actually does occur in practical work, and is not merely a theoretical consideration.

In conclusion, I should like to say that only the fringe of a very large subject has been touched, and that there are many other devices which may be used to help us towards our goal-the cure of disease.

\section{DISCUSSION.}

Mr. F. HARRISON GLEW, referring to the problem of protecting the skin of the patient, stated that long experience had shown him that ordinary table jelly satisfies all requirements in this connection. Its absorptive qualities are approximately the same as those of water, and it can either be moulded to any required shape or applied in the form of overlapping wedges for convenience in adjusting the thickness of the absorbing layer. 